\title{
Anaemia in schoolchildren in eight countries in Africa and Asia
}

Partnership for Child Development. Principal investigators: Andrew Hall ${ }^{1,2, *}$, Emily Bobrow ${ }^{3}$, Simon Brooker ${ }^{1}$, Matthew Jukes ${ }^{1}$, Kate Nokes ${ }^{1}$, Jane Lambo ${ }^{1}$ Helen Guyatt ${ }^{1}$, Don Bundy ${ }^{1}$, Sam Adjei $^{4}$, Su-Tung Wen ${ }^{4}$, Satoto ${ }^{5}$, Hertanto Subagio ${ }^{5}$, Mohammed Zen Rafiluddin ${ }^{5}$, Ted Miguel ${ }^{6}$, Sylvie Moulin '6, Joseph de Graft Johnson', Mary Mukaka ${ }^{7}$, Nathalie Roschnik ${ }^{8}$, Moussa Sacko ${ }^{9}$, Anna Zacher ${ }^{10}$, Bonifacio Mahumane ${ }^{10}$, Charles Kihamia ${ }^{11}$, Lillian Mwanri ${ }^{11}$, Simon Tatala ${ }^{11}$, Nicholas Lwambo ${ }^{12}$, Julius Siza ${ }^{12}$, Le Nguyen Bao Khanh ${ }^{13}$, Ha Huy Khoi ${ }^{13}$ and Nguyen Duy Toan ${ }^{13}$

'Scientific Coordinating Centre, Partnership for Child Development, Wellcome Trust Centre for the Epidemiology of Infectious Disease, Oxford University, South Parks Road, Oxford OXI 3FY, UK: ${ }^{2}$ Present address:

Helen Keller International, P.O. Box 6066, Gulshan, Dhaka 1212, Bangladesh: ${ }^{3}$ Save the Children Federation, 54 Wilton Road, Westport, CT 06880, USA: ${ }^{4}$ Ghana Partnership for Child Development, Health Research Unit, Adabraka, P.O. Box 184, Accra, Ghana: ${ }^{5}$ Partnership for Child Development (Mitra), Research Institute, University of Diponegoro, Semarang, Central Java, Indonesia: ${ }^{6}$ ICS Monitoring \& Evaluation, P.O. Box 599, Busia, Kenya: ${ }^{7}$ Save the Children Federation, NGO Onions Village, P.O. Box 30374, Lilongwe, Malawi: ${ }^{8}$ Save the Children Federation, Bamako, Mali: 'Institut National de Recherche en Santé Publique, B.P. 1771, Bamako, Mali: ${ }^{10}$ Save the Children Federation, Avenida Tomas Nduda, CP 1854, Maputo, Mozambique:

${ }^{11}$ Tanzania Partnership for Child Development, Ocean Road Hospital, P.O. Box 9383, Dar es Salaam, Tanzania:

${ }^{12}$ National Institute of Medical Research, Mwanza Research Centre, P.O. Box 1462, Mwanza, Tanzania:

${ }^{13}$ Viet Nam Partnership for Child Development, National Institute of Nutrition, 48 Tang Bat Ho, Hanoi, Vietnam

Submitted 10 April 2000: Accepted 16 October 2000

\begin{abstract}
Objective: To report on the haemoglobin concentrations and prevalence of anaemia in schoolchildren in eight countries in Africa and Asia.

Design: Blood samples were collected during surveys of the health of schoolchildren as a part of programmes to develop school-based health services.

Setting: Rural schools in Ghana, Indonesia, Kenya, Malawi, Mali, Mozambique, Tanzania and Vietnam.

Subjects: Nearly 14000 children enrolled in basic education in three age ranges (7-11 years, $12-14$ years and $\geq 15$ years) which reflect the new UNICEF/WHO thresholds to define anaemia.

Results: Anaemia was found to be a severe public health problem (defined as $>40 \%$ anaemic) in five African countries for children aged 7-11 years and in four of the same countries for children aged 12-14 years. Anaemia was not a public health problem in the children studied in the two Asian countries. More boys than girls were anaemic, and children who enrolled late in school were more likely to be anaemic than children who enrolled closer to the correct age. The implications of the four new thresholds defining anaemia for school-age children are examined.

Conclusions: Anaemia is a significant problem in schoolchildren in sub-Saharan Africa. School-based health services which provide treatments for simple conditions that cause blood loss, such as worms, followed by multiple micronutrient supplements including iron, have the potential to provide relief from a large burden of anaemia.
\end{abstract}

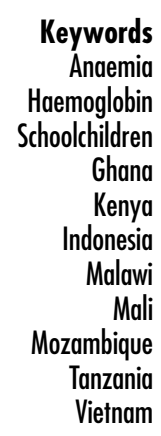

Iron-deficiency anaemia is probably the most widespread and common micronutrient deficiency in the world today and, because anaemia is associated with peri-natal mortality, the priorities of most anaemia-control programmes are pregnant women and young children ${ }^{1}$. Yet being anaemic has important consequences for all age groups because a low haemoglobin concentration can impair mental as well as physical performance. For example, a review of 
studies of school-age children, a group that is believed to be particularly vulnerable to the effects of ill health during a stage when they are both growing and learning, has reported that anaemia can affect cognitive function, motor performance and educational achievements ${ }^{2}$. Yet although something is known about the potential harm that anaemia causes to the school-age group in terms of child development, there is little recent information on the extent of anaemia as a public health problem. Here we present the findings of surveys which have measured haemoglobin concentrations while screening schoolchildren in eight countries in Africa and Asia, and we examine the prevalence of anaemia using recently revised UNICEF/WHO thresholds for the school-age group $^{3}$.

\section{Subjects and methods}

The data were collected during surveys of the health of schoolchildren in five countries participating in the Partnership for Child Development, or in satellite research studies, including Ghana, Kenya, Indonesia, Tanzania (two sites) and Vietnam; and in Malawi, Mali and Mozambique where Save the Children Federation (USA) is implementing school health programmes. Table 1 shows the location of each site. All schools were in rural areas. The age, sex and class of each child studied were recorded from school records.

A finger-prick blood sample was collected from each child using a sterile lancet, except in coastal Tanzania where venous blood was taken, and the haemoglobin concentration was estimated by means of a portable battery-operated haemoglobinometer (Hemocue, Angelholm, Sweden). This machine has been shown to give haemoglobin values in field studies that are highly correlated with values measured using a laboratory haemoglobinometer ${ }^{4}$. The machines were checked regularly with the reference cuvette. Anaemia was defined using the following age- and sex-specific thresholds proposed by UNICEF and the WHO: $<115 \mathrm{~g} \mathrm{l}^{-1}$ for

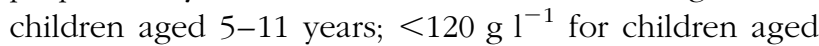
$12-14$ years; $<120 \mathrm{~g} \mathrm{l}^{-1}$ for girls $\geq 15$ years old; and $<130 \mathrm{~g} \mathrm{l}^{-1}$ for boys $\geq 15$ years old ${ }^{3}$. No corrections were made for altitude above sea level but the highest site, the lakeside site in Tanzania, was only about $1200 \mathrm{~m}$ above sea level.

Children are supposed to enrol in basic education in all countries when they are either 6 or 7 years old, but many enrol later than this. To capture late enrolment in school, an age-for-grade score was used in which a child enrolled at the correct age in the right class was given a score of zero, a child 1 year late in enrolling was given a score of -1 , a child 2 years late a score of -2 , and so on $^{5}$. This score assumes that it is not usual to retain children in the same class for more than one year. The prevalence of anaemia was then examined in each country by the agefor-grade score except in Vietnam, where children in only one class were studied, and in Mali because there are only two classes. Logistic regression was also used to examine the association between the prevalence of anaemia and the age-for-grade score while controlling for age and sex. Means were compared using Student's $t$-test.

\section{Results}

Table 1 shows the distribution by age and sex of the children studied in each country aggregated into the three age classes used for the UNICEF/WHO anaemia thresholds ${ }^{3}$. Table 2 shows the mean haemoglobin concentrations by sex and age class for all children in each country and for the two sites in Tanzania. In most countries, children aged 7-11 years had a haemoglobin concentration

Table 1 The location and characteristics of the surveys of schoolchildren and the sample sizes by age and sex

\begin{tabular}{|c|c|c|c|c|c|c|c|c|c|c|c|c|}
\hline \multirow[b]{3}{*}{ Country } & \multirow[b]{3}{*}{ Location } & \multirow[b]{3}{*}{ Year } & \multirow[b]{3}{*}{ Schools } & \multirow[b]{3}{*}{ Classes } & \multicolumn{8}{|c|}{ Age range } \\
\hline & & & & & \multicolumn{2}{|c|}{$7-11$ years } & \multicolumn{2}{|c|}{$12-14$ years } & \multicolumn{2}{|c|}{$\geq 15$ years } & \multicolumn{2}{|c|}{ Total } \\
\hline & & & & & Boys & Girls & Boys & Girls & Boys & Girls & Boys & Girls \\
\hline Ghana & Volta Region & 1994 & $\begin{array}{l}\text { Government Primary \& } \\
\text { Junior Sec. }\end{array}$ & $1-9$ & 455 & 452 & 635 & 649 & - & - & 1090 & 1101 \\
\hline Indonesia & $\begin{array}{l}\text { Central Java } \\
\text { Province }\end{array}$ & 1994-95 & Government Primary & $1-5$ & 776 & 739 & 287 & 251 & - & - & 1063 & 990 \\
\hline Kenya & Western Province & 1998 & Government Primary & $2-8$ & 86 & 110 & 202 & 191 & 74 & 54 & 362 & 355 \\
\hline Malawi & Southern Region & 1998 & Government Primary & $3,6 \& 7$ & 116 & 131 & 286 & 283 & 160 & 163 & 562 & 577 \\
\hline Mali & Sikasso Region & 1999 & $\begin{array}{l}\text { Community \& } \\
\text { Government Primary }\end{array}$ & 5 & 486 & 484 & 245 & 249 & 73 & 40 & 804 & 773 \\
\hline Mozambique & Gaza Province & 1999 & Government Primary & 4 & 104 & 115 & 309 & 339 & 70 & 35 & 483 & 489 \\
\hline $\begin{array}{r}\text { Tanzania } \\
\text { (coast) }\end{array}$ & $\begin{array}{l}\text { Tanga \& Pwani } \\
\text { Regions }\end{array}$ & $1995-97$ & Government Primary & $1-7$ & 654 & 808 & 721 & 709 & - & - & 1375 & 1517 \\
\hline $\begin{array}{l}\text { Tanzania } \\
\text { (lake) }\end{array}$ & Mwanza Region & 1997 & Government Primary & $1-7$ & 198 & 278 & 447 & 472 & 263 & 195 & 908 & 945 \\
\hline Vietnam & Ha Nam Province & 1998 & Government Primary & 4 & 293 & 295 & - & - & - & - & 293 & 295 \\
\hline Total & & & & & 3168 & 3412 & 3132 & 3143 & 641 & 487 & 6941 & 7042 \\
\hline
\end{tabular}


Table 2 Mean haemoglobin concentrations of schoolchildren by country, age class and sex

\begin{tabular}{|c|c|c|c|c|c|c|c|c|c|c|c|c|c|c|c|}
\hline \multirow{3}{*}{$\begin{array}{l}\text { Age range } \\
\text { Sex } \\
\text { Anaemia threshold }\end{array}$} & \multicolumn{5}{|c|}{$7-11$ years } & \multicolumn{5}{|c|}{$12-14$ years } & \multicolumn{5}{|c|}{$\geq 15$ years } \\
\hline & \multicolumn{2}{|c|}{$\begin{array}{c}\text { Boys } \\
<115 \mathrm{~g} \mathrm{I}^{-1}\end{array}$} & \multicolumn{2}{|c|}{$\begin{array}{c}\text { Girls } \\
<115 \mathrm{~g} \mathrm{I}^{-1}\end{array}$} & \multirow[b]{2}{*}{$P$} & \multicolumn{2}{|c|}{$\begin{array}{c}\text { Boys } \\
<120 \mathrm{~g} \mathrm{I}^{-1}\end{array}$} & \multicolumn{2}{|c|}{$\begin{array}{c}\text { Girls } \\
<120 \mathrm{~g} \mathrm{I}^{-1}\end{array}$} & \multirow[b]{2}{*}{$P$} & \multicolumn{2}{|c|}{$\begin{array}{c}\text { Boys } \\
<130 \mathrm{~g} \mathrm{I}^{-1}\end{array}$} & \multicolumn{2}{|c|}{$\begin{array}{c}\text { Girls } \\
<120 \mathrm{~g} \mathrm{I}^{-1}\end{array}$} & \multirow[b]{2}{*}{$P$} \\
\hline & Mean & SD & Mean & SD & & Mean & SD & Mean & SD & & Mean & SD & Mean & SD & \\
\hline Ghana & 118.2 & 13.6 & 119.2 & 13.6 & 0.297 & 124.7 & 14.1 & 127.3 & 14.0 & $<0.001$ & - & - & - & - & \\
\hline Indonesia & 120.4 & 13.6 & 122.5 & 11.6 & 0.002 & 124.7 & 13.1 & 126.0 & 14.2 & 0.257 & - & - & - & - & \\
\hline Kenya & 122.9 & 13.5 & 122.2 & 13.9 & 0.736 & 123.4 & 13.0 & 124.4 & 13.6 & 0.458 & 130.8 & 15.3 & 122.1 & 13.9 & 0.001 \\
\hline Malawi & 116.2 & 14.9 & 119.5 & 14.8 & 0.085 & 121.2 & 15.6 & 120.0 & 15.4 & 0.357 & 129.5 & 21.1 & 120.2 & 16.6 & $<0.001$ \\
\hline Mali & 110.3 & 12.5 & 112.7 & 13.6 & 0.004 & 116.4 & 13.3 & 118.1 & 14.2 & 0.162 & 116.2 & 15.6 & 114.8 & 16.3 & 0.644 \\
\hline Mozambique & 113.8 & 12.1 & 113.1 & 14.8 & 0.740 & 114.7 & 14.0 & 114.4 & 14.6 & 0.773 & 116.8 & 15.8 & 107.2 & 13.4 & 0.003 \\
\hline Tanzania (coast) & 110.5 & 14.1 & 111.2 & 13.1 & 0.311 & 112.1 & 14.9 & 112.3 & 13.4 & 0.869 & - & - & - & - & \\
\hline Tanzania (lake) & 112.8 & 12.9 & 114.3 & 13.0 & 0.200 & 112.5 & 15.8 & 114.6 & 13.2 & 0.025 & 118.8 & 14.7 & 116.5 & 14.0 & 0.090 \\
\hline Vietnam & 125.5 & 10.7 & 127.1 & 10.9 & 0.070 & - & - & - & - & & - & - & - & & - \\
\hline All sites & 116.8 & 14.4 & 117.7 & 14.1 & 0.020 & 118.1 & 15.6 & 118.9 & 15.2 & 0.030 & 122.6 & 18.0 & 117.6 & 15.4 & $<0.001$ \\
\hline
\end{tabular}

- denotes no data.

lower than children aged $12-13$ years. When data from all countries were aggregated (but excluding Vietnam where data for only one age class were available), the mean was significantly lower in the younger age class (116.3 vs. 118.5, $n=11135, P<0.001)$.

Figure 1(a) shows for all countries the prevalence of anaemia in boys and girls aged 7-11 years ranked by total prevalence, while Fig. 1(b) shows the same for children aged $12-13$ years. Figure 1 reveals a wide range with the lowest prevalence observed in the two Asian countries, although there was no significant difference between Indonesia and Kenya for the younger age class. There was a general overall trend for the prevalence of anaemia to be higher in boys than in girls, and this difference was more marked in the older age class. For boys in the age class 7-11 years, the overall risk ratio (RR) was just significant $(\mathrm{RR}=1.07,95 \% \mathrm{CI} 1.10-1.13, P=0.019)$; in the age class $12-14$ years the risk ratio for boys was 1.18 (95\% CI 1.12-1.24, $P<0.001$ ); and in the age class $\geq 15$ years the risk ratio for boys was 1.30 (95\% CI 1.16-1.46, $P<0.001)$.

Although the mean haemoglobin concentration of children aged 7-11 years was only slightly lower than among children aged 12-14 years (117.3 vs. 118.5, $P<0.001$ ), the prevalence of anaemia in the older age class was much higher $(40.2 \%$ vs. $54.4 \%$ respectively, $P<0.001)$ so that they were 1.35 times more likely to be anaemic (95\% CI 1.30-1.41).

The data from Tanzania show that the prevalence of anaemia can vary within a country. The mean haemoglobin concentrations of children in the two youngest age classes living on the coast of Tanzania were significantly lower than for children living near to Lake Victoria ( $P<0.001$ and $P=0.02$, respectively) and the prevalence of anaemia was also significantly greater at the coast (both $P<0.01$ ).

Figure 2 shows for four sites (Malawi, Kenya, Indonesia and coastal Tanzania) for which there was a satisfactory age range and reasonable sample sizes, how the mean haemoglobin concentration may change for each sex with age. In all countries, except Tanzania, the regression lines (not shown) indicate that the mean haemoglobin concentration of boys was higher for each year of age by between 1.4 and $1.7 \mathrm{~g} \mathrm{l}^{-1}$ per year; in Tanzania the rise was only $0.5 \mathrm{~g} \mathrm{l}^{-1}$ per year of age. Among girls in Malawi and Kenya the haemoglobin concentration was higher with age in a similar way to boys until about 14 years of age when the sexes diverged, so that late adolescent girls had a significantly lower haemoglobin concentration than boys of the same age (both $P<0.01$ ).

Figure 3 shows the relationship between the age-forgrade score and the percentage of children who were anaemic at sites where statistically significant trends were observed either in the regression line or in the logistic regression analysis. The linear regression lines (not shown) were statistically significant in Indonesia $(P<0.05)$, Kenya $(P<0.02)$, Mozambique $(P<0.01)$, Tanzania - coast $(P<0.001)$ and Tanzania - lake $(P<0.02)$. The logistic regression analysis showed that the relationship remained statistically significant when controlling for age and sex in all of the same sites except in Kenya, where the trend was no longer significant $(P=$ 0.227), and in Malawi where the relationship became statistically significant $(P=0.006)$.

The new WHO/UNICEF classification of anaemia $^{3}$ means that four different thresholds now apply to school-age children. Figure 4 shows how the different thresholds affect the relationship between the haemoglobin concentration and prevalence of anaemia among children in the two youngest age groups studied at all sites. It shows that, for each decrease in mean haemoglobin concentration of $1 \mathrm{~g}^{-1}$, the prevalence of anaemia increases by about 2.8\%; and that for the same mean haemoglobin concentration the $5 \mathrm{~g} \mathrm{l}^{-1}$ difference in threshold increases the prevalence of anaemia in the older age class by about $17.5 \%$. 

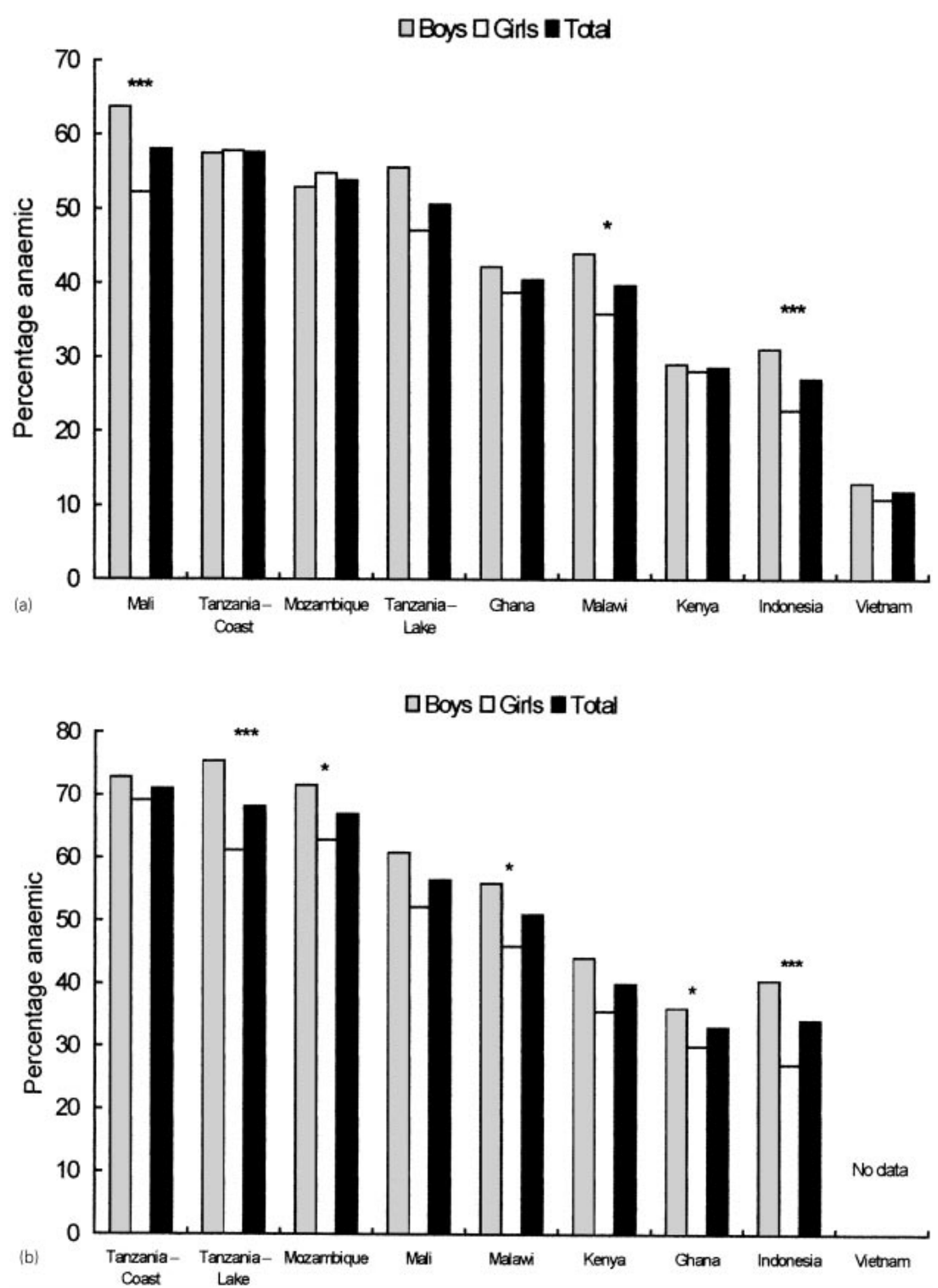

Fig. 1 The prevalence of anaemia in children in eight countries (and two sites in Tanzania), by sex and in total, in two age classes: (a) age 7-11 years; (b) age 12-14 years. The countries have been ranked by the prevalence of anaemia (Statistical significance of differences between the sexes: ${ }^{* \star *}$ denotes $P<0.001$; ${ }^{*}$ denotes $P<0.05$ )

\section{Discussion}

This analysis of the haemoglobin concentrations of nearly 14000 children enrolled in basic education in eight countries in Africa and Asia indicates a large burden of anaemia, mostly in Africa. If a prevalence of anaemia of $\geq 40 \%$ is used to indicate a severe public health problem $^{1,3}$, then in Ghana, Malawi, Mali, Mozambique and Tanzania anaemia would be of concern among children aged 7-11 years, and in four of these countries excluding Ghana - it would be of importance among children aged 12-14 years as well. The inaccurate recording of the age of children in rural African schools may lead to misclassification, but the extent of this is impossible to gauge. Anaemia did not appear to be a major public health problem in the samples of children studied in the two Asian countries.

The data indicate that the prevalence of anaemia has not changed much in Africa over the last 15 years: the prevalence of 50\% reported here among children aged $7-$ 11 years in the six African countries for which there are data is not substantially different from the $52 \%$ average reported when 43 studies of children aged 6-12 years were reviewed in $1985^{\circ}$.

Although there is an almost twofold range in the prevalence of anaemia, even in the five African countries, three important trends and patterns emerge. First, there is evidence in the two younger age classes shown in Fig.1 (which both have the same thresholds to classify children as anaemic) that boys are slightly more likely to be 

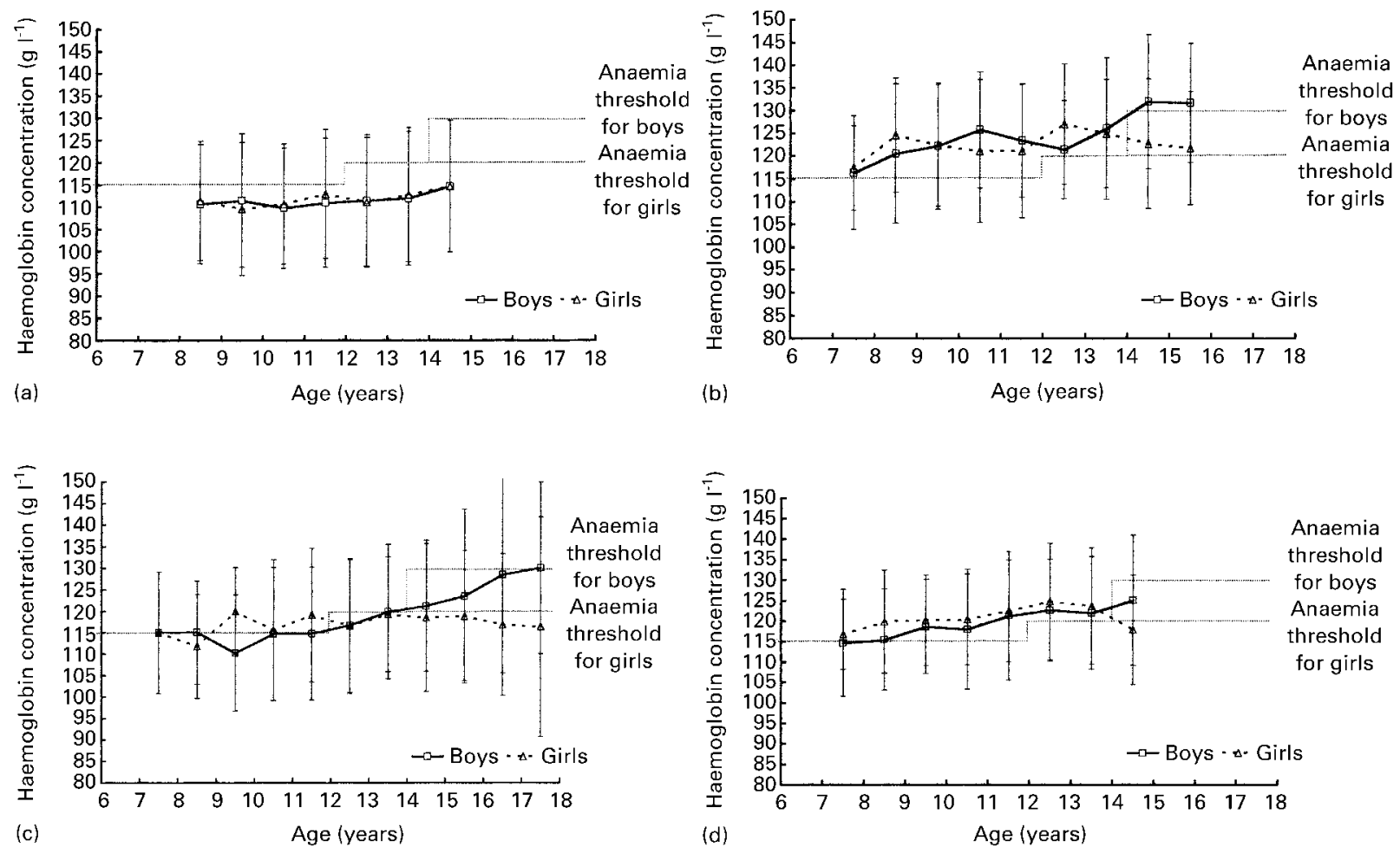

Fig. 2 The mean haemoglobin concentrations of school-age children, by sex, in four countries: (a) Tanzania (coast); (b) Kenya; (c) Malawi; (d) Indonesia. The dotted lines show the sex- and age-specific thresholds below which anaemia is defined

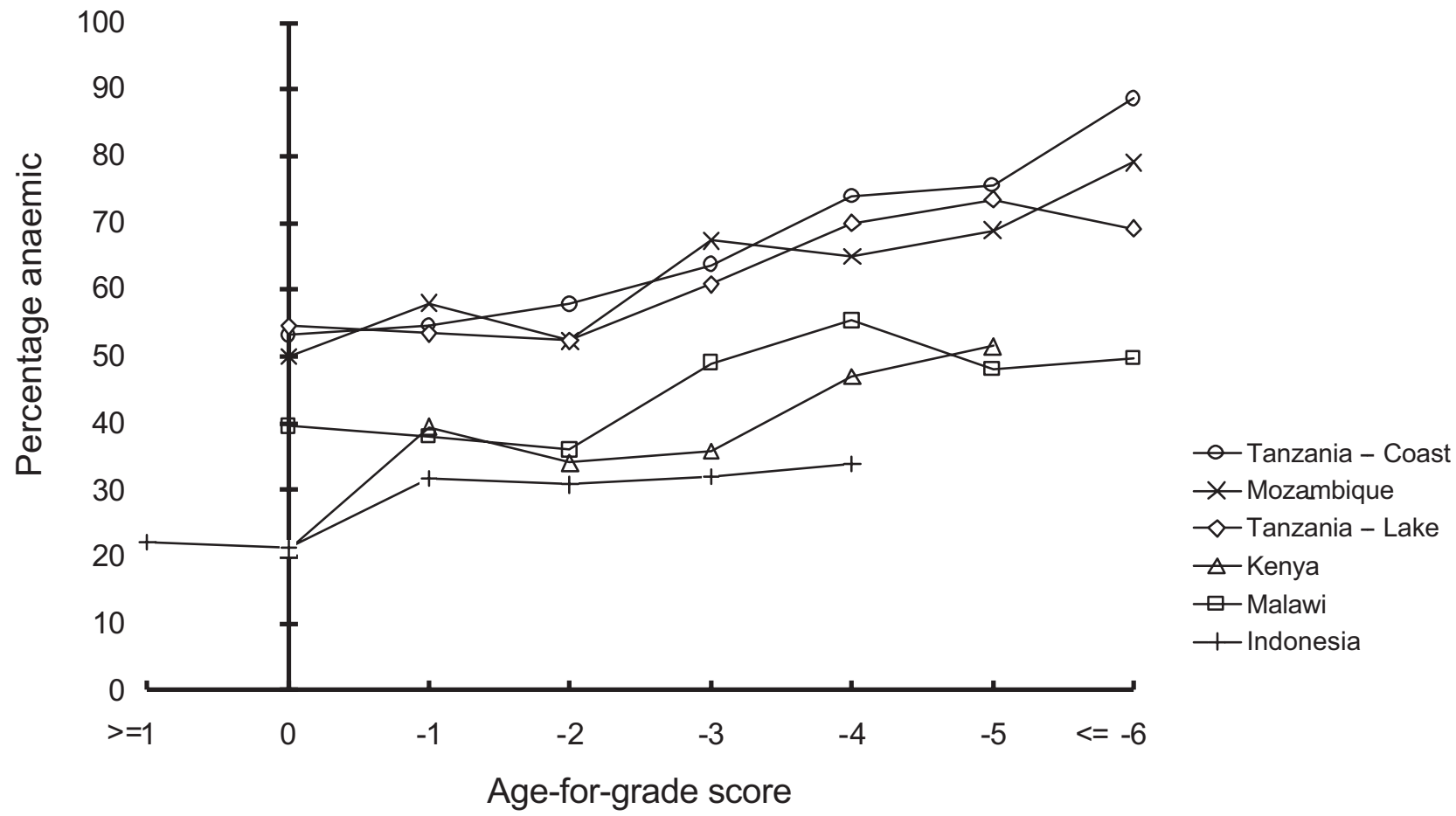

Fig. 3 The relationship between the mean haemoglobin concentration and an age-for-grade score, an index of late enrolment in school (see Methods), in five countries and at two sites in Tanzania 


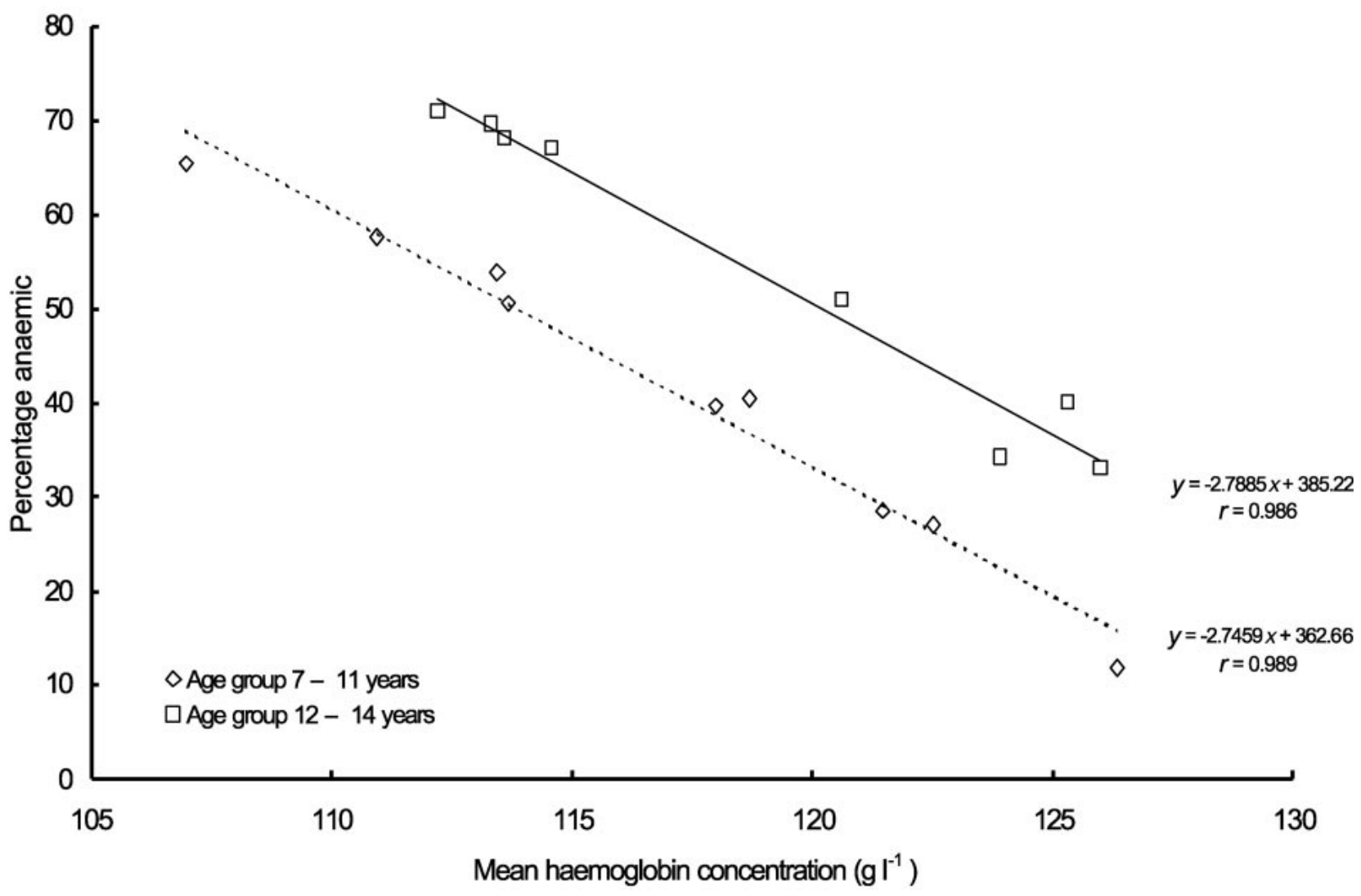

Fig. 4 The relationship between the mean haemoglobin concentrations and the prevalence of anaemia in children in eight countries using data for two different age groups and their age-specific thresholds: $<115 \mathrm{~g} \mathrm{I}^{-1}$ for children aged $7-11$ years and $<120 \mathrm{~g} \mathrm{I}^{-1}$ for children aged 12-14 years ${ }^{3}$. The equations for the lines and the correlation coefficient $(r)$ are also given

anaemic than girls, although the means were only significantly different between the sexes in Indonesia among children aged 7-11 years, and in Ghana and lakeshore Tanzania among children aged $12-13$ years (Table 2). Although the mean haemoglobin concentration of boys in the late adolescent age class was higher than for girls in all four countries for which there were data, because boys are classified as anaemic at a higher threshold than girls (130 vs. $120 \mathrm{~g} \mathrm{l}^{-1}$ ), more adolescent boys than girls were thus classified as anaemic. The implication of this observation is that adolescent boys should also be targets of anaemia-control programmes as well as adolescent girls, the usual group of concern.

Second, there is evidence that the youngest children tend to have the lowest mean haemoglobin concentration and that mean haemoglobin concentrations tend to rise with age (Table 2). Although this is true, because of the change in haemoglobin threshold at which children are classified as anaemic at 12 years of age, anaemia is more common in the 12-14 year age class than in children aged 7-11 years, as Fig. 4 shows. The data presented in Fig. 2 for children in four countries show an apparent increase in haemoglobin with age for both sexes until around 14 years old, a trend that has already been reported for schoolchildren in the lake region of Tanzania ${ }^{7}$. At around
14 years of age, the mean haemoglobin concentrations of boys and girls in Kenya, Malawi and at the lakeshore site in Tanzania ${ }^{6}$ tend to diverge. This is not surprising given the greater requirement for iron by girls at menarche ${ }^{8}$ but perhaps it is a little later in age than might be expected. There is evidence, however, from countries such as Nigeria $^{9}$ and South Africa ${ }^{10}$ that menarche may be delayed due to under-nutrition, which may explain why the divergence occurs in the middle of what is usually viewed as adolescence. The WHO defines adolescence as 10-19 years of age ${ }^{11}$.

Third, the association between late enrolment in school and a higher prevalence of anaemia shown in Fig. 3 may simply reflect the fact that such children are more undernourished than children who enrol nearer the right age. We have shown a similar association between the age-for-grade score and $Z$-scores of height-for-age (an index of stunted growth) in both Ghana and Tanzania ${ }^{4}$.

The schoolchildren we studied may not necessarily be representative of school-age children in each country as a whole for two reasons. First, they were typically drawn from only one region, and the data from Tanzania show that there may be significant differences between regions. Second, only children enrolled in school were studied and in some places non-enrolled children may be more 
anaemic than those in school. For example, a study in Ghana found a greater proportion of non-enrolled adolescent boys were anaemic when compared with boys matched for age who were enrolled in school; the difference was attributed to heavier infections with Schistosoma haematobium ${ }^{12}$. There are also statistical limitations to the data because some of the sample sizes of disaggregated groups are small.

The fact that four different thresholds of haemoglobin concentration are now applied to school-age children to define anaemia has complicated the assessment of anaemia in this large and important age group. Figure 4 shows the effect of the different thresholds on the prevalence of anaemia in the two youngest age groups. For the same mean haemoglobin concentration, the roughly $4 \%$ higher threshold used for the older children (115 vs. $120 \mathrm{~g} \mathrm{l}^{-1}$ ) leads to a nearly $18 \%$ higher prevalence of anaemia. And although boys aged $\geq 15$ years have a higher mean haemoglobin concentration than girls of the same age range, more adolescent boys are classified as anaemic. The new thresholds may have been selected for good physiological reasons but they have large effects on the prevalence of anaemia and thus of anaemia as a public health problem. When these thresholds are applied it seems that all age groups of schoolchildren could benefit from efforts to improve haemoglobin concentrations and reduce the prevalence of anaemia. A variety of options are open.

First, the diet of children could be improved. The amount of iron in the diet and its bioavailability are major factors contributing to anaemia ${ }^{13}$. But the solutions to this problem, which include eating good sources of absorbable iron such as meat and consuming vitamin $\mathrm{C}$ to promote iron absorption, are typically beyond the means of poor families, let alone are factors within the control of children. Fortification of foods is also unrealistic in circumstances where little if any factory-processed food is bought. Treating parasitic worms which cause blood loss, such as hookworm and Schistosoma spp., and controlling malaria can lead to improvements in haemoglobin concentrations, which shows that they have a causative role in anaemia ${ }^{14-17}$.

Another potential intervention to improve haemoglobin concentrations is iron supplements, which may be most effective when given with other micronutrients. Supplements containing iron typically have to be given over a period of weeks if not months, which raises questions of delivery and compliance. One opportunity that is being increasingly explored by means of large-scale operations research is delivery through schools. Experiences in countries such as Ghana, Tanzania and Mexico have shown that children can be dewormed on a mass basis with safe, inexpensive and highly effective single-dose anthelmintic drugs ${ }^{18,19}$. The school system may also provide a mechanism to deliver iron supplements to children after deworming, or perhaps better still, the multiple micronutrient supplements that are now being promoted by the WHO and UNICEF ${ }^{20,21}$. These experiences and developments suggest that the continuing public health problem of anaemia in school-age children highlighted in the surveys reported here is potentially solvable, and perhaps sooner rather than later.

\section{Acknowledgements}

The Partnership for Child Development and its satellite research studies are supported by the United Nations Development Programme, the Rockefeller Foundation, the Edna McConnell Clark Foundation, the James S. McDonnell Foundation, the Wellcome Trust, the World Bank, the United Nations Children's Fund (UNICEF) and the World Health Organization (WHO). The programmes of the Save the Children Federation (USA) in Mali and Mozambique are supported by the United States Agency for International Development (USAID) and in Malawi by a private donor.

\section{References}

1 Stoltzfus RJ, Dreyfuss ML. Guidelines for the Use of Iron Supplements to Prevent and Treat Iron Deficiency Anaemia. INACG/WHO/UNICEF. Washington, DC: ILSI Press, 1998.

2 Nokes C, van den Bosch C, Bundy DAP. The Effects of Iron Deficiency and Anemia on Mental and Motor Performance, Educational Achievement, and Behaviour in Children. An Annotated Bibliography. Washington, DC: INACG and ILSI Press, 1998.

3 WHO. Iron Deficiency Anaemia: Assessment, Prevention and Control. Geneva: World Health Organization, 2000 [in press].

4 Hudson TM, Bingham KC, Simmons WK. An evaluation of the HemoCue for measuring haemoglobin in field studies in Jamaica. Bull. World Health Org. 1994; 72: 423-6.

5 PCD (Partnership for Child Development). Short stature and the age of enrolment in primary school: studies in two African countries. Soc. Sci. Med. 1999; 48: 675-82.

6 DeMaeyer E, Adiels-Tegman M. The prevalence of anaemia in the world. World Health Stat. Quart. 1985; 38: 302-16.

7 Lwambo NJS, Brooker S, Siza JE, Bundy DAP, Guyatt H. Age patterns in stunting and anaemia in African school children: a cross-sectional study in Tanzania. Eur. J. Clin Nutr. 2000; 54: 36-40.

8 Fairweather-Tait SJ. Iron requirements and prevalence of iron deficiency in adolescents. An overview. In: Hallberg L, Asp N-G, eds. Iron Nutrition in Health and Disease. London: John Libbey \& Co., 1996; 137-48.

9 Fakeye O, Adegoke A. The characteristics of the menstrual cycle in Nigerian schoolgirls and the implication for school health. Afr. J. Med. Sci. 1994; 23: 13-7.

10 Cameron N, Grieve CA, Kruger A, Leschner KF. Secondary sexual development in rural and urban South African black children. Ann. Hum. Biol. 1993; 20: 583-93.

11 WHO. A Picture of Health? A Review and Annotated Bibliography of the Health of Young People in Developing Countries. Geneva: World Health Organization, 1995.

12 Fentiman A, Hall A, Bundy DAP. Health and cultural factors associated with enrolment in basic education: a study in rural Ghana. Soc. Sci. Med. 2001; 52: 429-39. 
13 Tatala S, Svanberg U, Mduma B. Low dietary iron availability is a major cause of anemia: a nutrition survey in the Lindi District of Tanzania. Am. J. Clin. Nutr. 1998; 68: 171-8.

14 Roche M, Layrisse M. The nature and causes of hookworm anaemia. Am. J. Trop. Med. Hyg. 1966; 15: 1031-110.

15 Stephenson LS, Latham MC, Kurz KM, Kinoti SN, Oduori ML, Crompton DWT. Relationship of Schistosoma haematobium, hookworm and malaria infections and metrifonate treatment to hemoglobin levels in Kenyan school children. Am.J. Trop. Med. Hyg. 1985; 34: 519-28.

16 Stoltzfus RJ, Chwaya HM, Tielsch JM, Schulze KJ, Albonico M, Savioli L. Epidemiology of iron deficiency anemia in Zanzibari schoolchildren: the importance of hookworms. Am. J. Clin. Nutr. 1997; 65: 153-9.

17 Kurtzhals JA, Addae MM, Akanmori BD, Dunyo S, Koram KA, Appawu MA, Nkrumah FK, Hviid L. Anaemia caused by asymptomatic Plasmodium falciparum infection in semiimmune African schoolchildren. Trans. R. Soc. Trop. Med. Hyg. 1999; 93: 623-7.

18 WHO. Report of the WHO Informal Consultation on the Use of Chemotherapy for the Control of Morbidity due to Soiltransmitted Nematodes in Humans. WHO/CTD/SIP/96.2. Geneva: World Health Organization, 1996.

19 PCD (Partnership for Child Development). The cost of largescale school health programmes which deliver anthelmintics to children in Ghana and Tanzania. Acta Tropica 1999; 73 : 183-204.

20 Ndossi G, Taylor A. Multiple Micronutrient Supplementation in Tanzania. Dar es Salaam, Tanzania: UNICEF, 1999.

$21 \mathrm{UNICEF} / \mathrm{MoH}$ Brazil. Micronutrient Supplementation through the Life Cycle. Report of a Workshop in Rio de Janeiro, 17-19 November 1999. 